Margit Koemeda-Lutz

Is there Healing Power in Rage?

\title{
蓲 Psychosozial-Verlag
}


Bibliographic information of Die Deutsche Nationalbibliothek (The German Library) The Deutsche Nationalbibliothek lists this publication in the Deutsche Nationalbibliografie; detailed bibliographic data are available at http://dnb.d-nb.de.

2006 Psychosozial-Verlag GmbH \& Co. KG, Gießen, Germany

info@psychosozial-verlag.de

www.psychosozial-verlag.de

\section{(c) $\underset{\mathrm{BY}}{\mathrm{N}} \Theta$}

This work is licensed under the Creative Commons Attribution-NonCommercialNoDerivatives 4.0 International License (CC BY-NC-ND 4.0). This license allows private use and unmodified distribution, but prohibits editing and commercial use (further information can be found at: https://creativecommons.org/licenses/by-nc-nd/4.0/). The terms of the Creative Commons licence only apply to the original material. The reuse of material from other sources (marked with a reference) such as charts, illustrations, photos and text extracts may require further permission for use from the respective copyrights holder.

Cover image: Ferdinand Hodler Ausschreitende Frau ,1910, oil on canvas, 48,5 x $39 \mathrm{~cm}$

https://doi.org/10.30820/0743-4804-2006-16

ISBN (PDF-E-Book) 978-3-8379-6879-8

ISBN (Print) 978-3-89806-517-7

ISSN (Online) 2747-8882 · ISSN (Print) 0743-4804 


\title{
Is there Healing Power in Rage? The Relative Contribution of Cognition, Affect and Movement to Psychotherapeutic Processes ${ }^{12}$
}

\author{
Margit Koemeda-Lutz
}

\section{Summary}

The question of what people need in order to change is still open to debate. The paper reviews evidence for when cognitive clarification and insight needs to be accompanied by emotional arousal, containment and / or expression and how motor activity facilitates experiential and / or behavioral change. A ficticious case is presented in order to illustrate different approaches for a first session. The paper reviews some neurobiological findings on the interactive modulation of unconscious and conscious levels of experiencing and behavior. A pilot study is reported in which the induction of hyperventilation and two bioenergetic exercises were examined with respect to their relative potency to facilitate psychosomatic change.

Key words: Body psychotherapy, emotion, motor behavior, neuroplasticity, unconscious behavior control

\section{A Ficticious Case Report}

Let me use a cartoon by F.K. Waechter in order to approach the question raised in my heading:

1 Koemeda-Lutz (2002)

2 Koemeda-Lutz (2005) Revised Version of a lecture held at the Vienna Symposium »Psychoanalysis and the Body«, 17.-19.September 2004, Running Title: »Therapeutic Interaction: The Macro- and the Micro-Perspective«. 
This image cannot be reproduced for copyright reasons.

F.K.Waechter "Ich liebe das Leben" 
Is there Healing Power in Rage?

This image cannot be reproduced for copyright reasons. 
If one of the portrayed persons should seek help from a psychotherapist, it would probably be the one on the right hand side. The problem presented may be the following: »I contact people in an absolutely positive way and very often get aggressive and negative responses. I wonder why this is so? He then tells a story like the one you can see in the cartoon. How would you begin therapy with such a patient? I would like to outline three possibilities:

Possibility A: The therapist proceeds with verbal explorations of what the patient told her, like: »Whose or which life do you enjoy? « And according to what his response is: »Exactly what is it that you enjoy in your life or in the life of XY? « And: »Could you describe a specific situation, in which you especially enjoyed this life, and maybe another one, in which you didn't enjoy it so much? « This way, the therapist could find out about linguistic representations of the patient's experiences. Are they well differentiated? Is his thinking complex? Does it match her models of human interactions or is it completely different? (cf. Bandler \& Grinder 1981; Boothe 1991; 1993; Boothe et al. 2002).

Possibility B: Still in the realm of linguistic representations, the therapist could explore emotional aspects of this person's experiencing. She could ask him, for example, to describe as precisely as possible what he felt when he addressed that man and those two women. She then asks what he felt when these people did not answer at first. Did he register an emotional change when he uttered »I enjoy life« a second time? Etc.

Possibility C: The therapist focuses her attention on nonverbal aspects in her interaction with the patient. She heard the person ring the doorbell - did it sound reluctant? Demanding? She saw the patient enter her office - how was his outer appearance? She felt his hand while saying »Hello, how do you do? « Was it limp? Firm? Warm? She heard his voice, observed his breathing while he was talking. She registered lots of counter-transferential reactions within herself - like, for instance, a slight feeling of repulsion, of pity or irritation. Whatever (...) She now says to him: »I enjoy life! What a wonderful phrase! Would you be willing to engage in a little experiment?« 


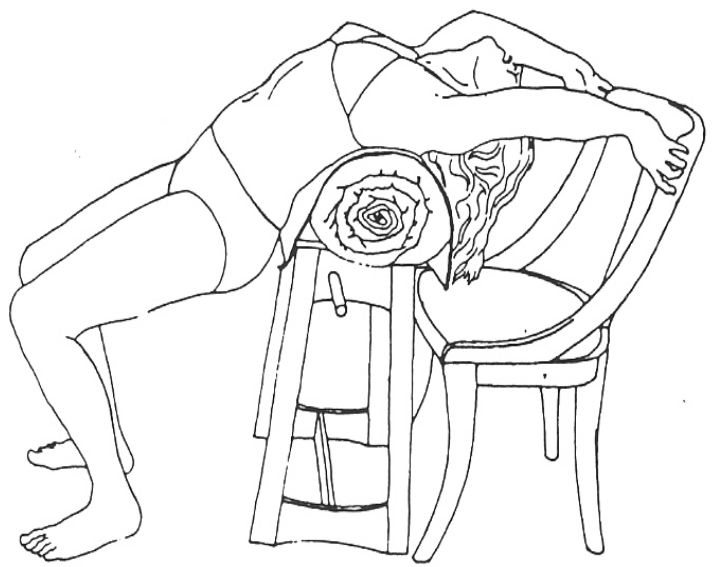

Transition from verbal levels to a level of (inter-) action: leaning backwards over the Bioenergetic Stool (Lowen E Lowen 1979)

The therapist pulls the Bioenergetic Stool into the middle of the room and asks her patient if he is ready to start an exercise, which might be a bit demanding physically (Lowen \& Lowen 1979; Dietrich \& Pechtl 1990) but could, on the other hand, help bring his body sensations into his focused attention. This would yield little specimens of an ongoing process of »life«, and his feelings as they change from moment to moment could be further explored.

Let's say the patient agrees to start this little experiment, the therapist then asks him to lean backwards over the stool and helps him find a position, which he could probably tolerate for a little while. Then, she suggests that he close his eyes, open them, close them again, concentrate on his breathing, breathe more deeply if possible, and slowly inhale and exhale.

In the meantime, the therapist collects several additional clinically relevant observations. They refer to some of the patient's physical characteristics (like elasticity or rigidity, spontaneous breathing patterns etc.) but also to the very specific pattern of this patient's interaction with her. All this information leads to formulating hypotheses of transference and counter-transference (e.g. Does the patient behave submissively to the therapist's instructions? Or are there little power struggles evolving? Is there a hint of threat in the air? Does the patient exhibit any signs of fear?). All this information will influence the unfolding process of interaction. 
If no serious disruptions occur, the therapist also asks the patient to carefully register all sensations arising during the exercise and, if possible, to think the sentence »I enjoy life! «, intermittently speak it out loudly, pay attention to the tone of his voice, maybe sing and/or yell the sentence, and possibly just select a single word like »I« or »life« or to just hum, whisper or scream single vowels like »a« or »e«.

In summary, hypotheses can be derived from each of the three possibilities proposed. Each hypothesis could guide subsequent efforts of exploration and intervention:

Referring to possibility A: The patient may be stunned by the question »Whose life«? His »joy of life« may have been traumatized at a very early stage and may have become fixed at a completely undifferentiated level of development. He feels attracted by the erotic-sexual aura around the two women and the man and he may feel some longing to merge (longing for intra-uterine bonding sensu Keleman (1986, 1987); a schizoid inclination according to Lowen (1981)). The full breasts and well-rounded outlines of the female and male bodies might promise some very desirable, never experienced abundance to him which would hint to an oral deficit according to Bioenergetic terminology (Lowen 1981). In any case, his being verbally undifferentiated would let us assume an early disorder where any reliable self-/object-differentiation has not yet occurred.

Proceeding with the possibility of $\mathrm{B}$, one could find out about the extent to which emotional processes are accessible to conscious experiencing, how they are represented linguistically and which mechanisms of emotional regulation the patient prefers. Are the patient's »I am so positive and kind « and »Why are other people so negative and mean? « his only explanations for his experience? Is he conscious of additional wishes or needs, like wanting to belong, be nourished, or be cared for? Does he perceive parallel feelings, like frustration, when he gets no reaction to his first attempt of making contact; or fear, when the man gets angry?

With possibility C, all cognitive-linguistic representations are treated as background information. An attempt is made to co-create a sequence of present experience. This is not spontaneous »enactment « for which Heisterkamp's book (2002) gives so many wonderful examples and to whose assessment and estimation it contributes so substantially - the therapist here, 
guided by her hypotheses, "puts on stage « some of the patient's typical psychosomatic patterns of functioning in order to make them accessible to consciousness and possibly to change. Variations in the rhythm and volume of breathing as well as muscular strain can destabilize the patient's habitual homoeostasis. Thereby, emotions may come to the surface, emotions that are normally suppressed or avoided (either because they are too painful or because they usually trigger negative reactions in the environment). If the sentence »I enjoy life « is connected to such altered psychosomatic states, it can either be decoded as a defensive statement instead of a much more deeply felt »I wish I were dead! « Or, the juxtaposition of the original statement and increasingly unpleasant body sensations reveals its absurdness and leads to collapse and surrender into one's own despair, which had been denied so far and could be paraphrased by »I wish I could live! «.

Klopstech (2002) calls this simultaneity of a bodily, emotional and cognitive insight an »energetic insight «. It seems to be a synergetic process on several levels. To use a physical metaphor (Haken 2002, S.84), one could also call it »laser-insight «. Synchronized oscillations of electrons produce coherent light in laser beams. One could think of synchronized patterns of neuronal firing going along with such insights, which most likely would be of more than normal intensity and impact.

\section{Why the Body Needs to be Involved in Psychotherapy}

Now, I wish to shift our focus to some neurobiological aspects of human thinking, feeling and behavior. I mainly refer to publications by Damasio (1995, 2000), Roth (1994, 2001), Ruegg (2001), Schiepek (2003), Schore (1994), Siegel (1999) and Spitzer (2002). I would like to concentrate on aspects relevant to psychotherapeutic processes:

Here are two guiding hypotheses:

\section{Each Experience Leaves an Imprint:}

Social interaction and communication, and particularly psychotherapentic processes, leave physically detectable imprints in human bodies.

Bioenergetic Analysis has traditionally focused on how social interaction and psychotherapy - visibly shape and change our bodies (posture and 
movement; e.g. Reich 1933; Lowen 1958). But as we learn - and this is a lifelong process - every new experience leaves - maybe invisible to the human eye - morphological and functional traces in our bodies - plastic or degenerative changes, displacements of norms in regulatory systems, as well as re- or new connections in neuronal cell assemblies.

Already in utero our brain appraises all events in our body according to the rules of implicit, associative, unconscious learning, applying the criteria »good, pleasant, successful « versus »bad, painful, unsuccessful « and stores these appraisals in our emotionally dominated memory of experiences (Roth 2003, 2004), the implicit memory. During our first weeks and months as infants this part of our memory is especially susceptible to being shaped. Cognitive, affective and motor patterns and routines of functioning develop dependent on current somatic and central nervous stages of maturity. Some of them are genetically determined, others optimally adjust to the given environmental conditions and opportunities for interaction (Skinner 1953, 1971, 1974; Stern 1992, Dornes 1993, 1997). What we call personality or character gradually forms from this (Lowen 1958, Johnson 1994).

A study carried out by Freeman et al. (1991) with rabbits seems illustrative here. The authors analyzed EEG recordings from a grid of electrodes.
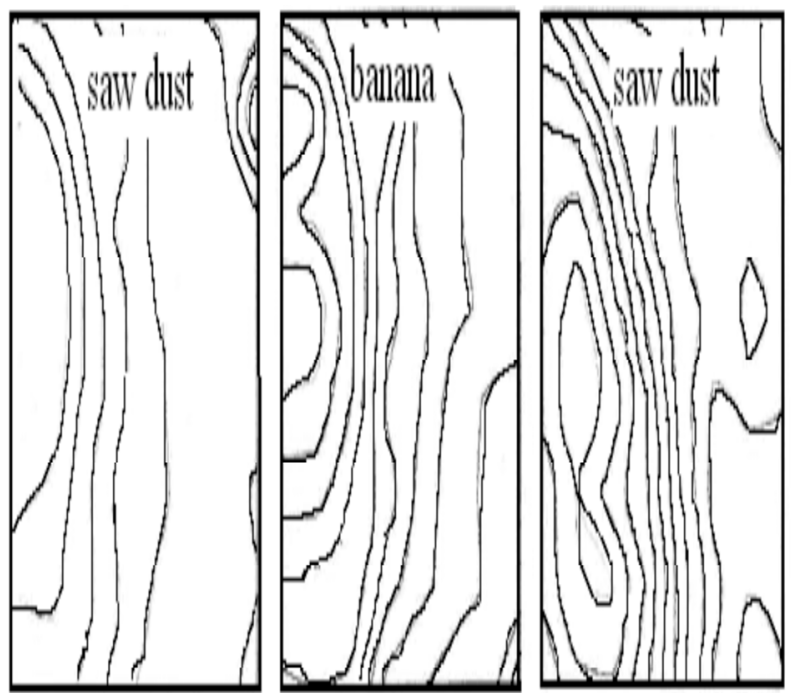

Changing patterns of neural activity in rabbits dependent on varying stimuli in different contexts (after Freeman et al. 1991) 
They showed that a certain smell (e.g. saw dust or bananas) elicited collective bursts of discharge in particular neuronal assemblies of the entorhinal bulb. In addition, they could demonstrate that these patterns of activity were determined by the experience the animal had made previously rather than by the stimulus itself. Activation patterns changed according to which other smells the animals had been exposed to. Summations of local amplitudes delineate areas of varying neural activity - comparable to altimetry lines on geographical maps. Activation configurations in rabbits which had learned to associate the smell of saw dust with being rewarded by a titbit offered, varied according to whether this association was new or recurring after an intermediate trial where the titbit was associated with the smell of bananas (compare the left and the right hand side profile of amplitudes).

Meanwhile there exist a number of studies, which demonstrate that psychic disorders are associated with altered dynamics of neural activities, i.e., they manifest somatically (e.g. Vaitl et al. 2003). Depressive disorders, for example, are frequently characterized by a certain hyperactivity of the hypothalamic-pituary-adrenal (HPA) axis.

Under specific environmental conditions, like prolonged stress, molecular and structural changes can be observed: e.g. an up-regulation of alpha ${ }_{2}^{-}$ adrenoceptors (after an initial down-regulation during 2-10 days), a decrease in the number of dendrite branches in pyramid neurons of the hippocampus, a decreased rate of neural generation and a reduction of volume in the hippocampus formation. Chronic stress causes a lack of noradrenaline in the brain. The number of presynaptic adrenoceptors decreases. Postsynaptic adrenoceptors decrease before they increase. In animal studies the application of antidepressants restituted neuroplasticity (Fuchs und Flügge 2004).

Pharmacological treatment in humans also effects in neurophysiological change. More remarkable though is the finding that purely psychotherapeutic treatment likewise caused - physically and neurophysiologically detectable changes indicating normalization (e.g. Martin Sölch 2004).

For psychotherapists the question arises: Can we generate sufficiently precise, (neuro-) biologically informed models of our patients' psychosomatic states? And, based on such representations, how can we trigger processes of development, growth and self-organization? 


\section{Rehabilitation of a Concept: The Unconscious:}

A considerable proportion of behavior control in bumans, as well as intra- and interindividual regulation, functions without our consciousness being involved.

In academic psychology, especially in the empiric-positive approach, the concept of the unconscious used to be banished, it was an embarrassment. Only recently has it reentered the mainstream scientific discourse through the side door of the neurosciences.

Recent studies inform us more precisely about the cerebral structures and mechanisms involved in the control of our behavior. Freud's assumption that the unconscious dominates the conscious Ego in controlling our actions receives support from current results of neuroscientific research.

Roth (2004, p.59 f.) defines consciousness as "a bundle of - content-wise very different states which only converge in the fact that they can be experienced consciously and are accessible to linguistic representation «.

Consciousness includes (according to Roth 2003, p. 31) the following manifestations:

1) external and internal perceptions

2) thoughts, imaginations, memories

3) feelings and needs

4) a sense of identity, a sense of Me, a sense of the somatic self

5) authorship and control over one's behavioral and mental acts

6) the ability to locate one's somatic self in space and time

7) the distinction between real experiences and fantasies.

According to our present neuroscientific knowledge all states of consciousness are necessarily linked to activities of the cerebral cortex, especially the association areas where sensory information is integrated with cognitive and emotional memories.

Manifestations of the unconscious are as follows, again according to Roth (2004, p. 63):

1) Preconscious and subliminal perceptions and sensory input beyond our focus of attention (during the first $250-500 \mathrm{~ms}$ all stimuli are subject to unconscious processing; most stimuli are too weak or too short in duration to reach our consciousness; nevertheless they often influence our behavior).

2) All perceptive, cognitive and emotional processes in the brain of the fetus, the infant, the toddler before the maturation of the association areas in 
the cortex. The hippocampus »organizing « memory and the cerebral cortex as the »data bank « for memory content do not attain maturity before the end of the third year of life.

3) »Forgotten « entries (= most entries) of the declarative or explicit memory; they as well frequently influence our attention, our thoughts and ideas.

4) Consolidated entries of the procedural or implicit memory: e.g. skiing (While we train certain movements or skills, an increased neural activity can be observed in the parietal and pre-motor cortex, later in the basal ganglia and cerebellum (= subcortical centers responsible for active behavior). Such behavior can be initiated consciously, but it later proceeds automatically and predominantly without conscious involvement.

5) Entries of the emotional memory, which form our personality, conditioned behavior and reflexes (they can be of varying generalization, e.g. fear of male persons; fear of male authorities only).

\section{Examples of Unconscious Regulatory Processes in the Human Body}

There are a variety of interdependent regulatory subsystems in the human body, which functionally organize and monitor their norm values and balances without our consciousness being involved.

a) There exists, for instance, a mostly »autonomously « functioning neural network in our viscera, called by some authors (e.g. Gershon 1998, 1999, Mayer 1999) our »second brain « or »visceral brain«. Neural afferents to the brain seem to exceed by far the strength of the efferents. To put it differently: More information goes toward rather than from the brain. Our viscera inform us how we feel. To a lesser extent moods may be generated in our cortices to then influence our somatic states.

b) The brain stem controls our autonomous functioning. It comprises important relays, »negotiating « between afferent information from the periphery of the body, from the viscera and inner organs, and efferent signals to them. These nuclei effect regulations without this information and these processes being transmitted to higher centers in the brain, let alone to our consciousness (Schiepek et al. 2003). 
c) A major part of stimulus processing and response preparation is carried out on subcortical levels, especially in the limbic system. Pathways which, in processing visual, auditory, gustatory, olfactory stimuli and stimuli relevant to pain, lead from the amygdala to the iso-cortex and the associative cortex, respectively, are stronger than those heading in the opposite direction. The amygdala influences the hormonal and autonomous nervous system both directly and via the hypothalamus. In animal studies certain nuclei of the amygdala have been shown to display changes in activity, before temporally correlated actions and responses to external events could be observed (Schulz et al. 1986, Langhorst et al. 1987).

A remarkable number of external and internal perceptions does not reach our consciousness, but is processed by subcortical centers (visual stimuli, e.g., by certain nuclei of the hypothalamus) and initiates from there autonomous and motor reactions. Ledoux $(1993,1994)$ demonstrated that seeing a snake immediately causes an increase in heart rate (...) several hundreds of milliseconds before the person identifies the snake consciously as a snake and feels fear.

d) Several studies have demonstrated that changes in somatic rhythms (beart, breath, brain stem, EEG) play a significant role in the novel organization of central nervous networks and their processing of stimulus patterns and also bring about changes in the coordination of subsystems (e.g. rhythms of discharge in certain nuclei of the amygdala, formatio reticularis and in the cardiovascular system; see e.g. Vanderhouten 1998, Vanderhouten et al. 2000, Lambertz \& Langhorst 1998, Lambertz et al. 2000, cited after Schiepek, p.6).

e) Especially important for psychotherapeutic processes seems to be the finding that what we experience as actions of free will is essentially prepared and determined by unconscious processes (Roth 2001, 2003). Event-correlated potentials of readiness in the supplementary and premotor cortex occur about 2-1 seconds before the pertaining behavior, e.g. the movement of a finger; correlated potentials in the prefrontal and association cortex, a prerequisite for motivational and conscious processes occur several hundreds of milliseconds later. Consciousness or an act of free will obviously function as epiphenomena of basically unconscious processes of behavior control. Our consciousness confabulates post festum rationalizations for manifested behavior. 
Cortical processes accompanied by consciousness do not control themselves but are determined by subcortical centers (e.g. thalamus, mesolimbic system, basal anterior cortex, formatio reticularis), which themselves function completely unconsciously and "autonomously«, controlled for instance by rhythmically released neuromodulators (acetylcholine, noradrenaline, dopamine und serotonine). These cause shifts in neural connectivity which are, according to Ciompi (1982, 1997) or Horowitz (1987), experienced as largely distinct states of mind (as a body-psychotherapist I would add: psychosomatic states).

These above results lead - I believe - to the conclusion that we must acknowledge and pay attention to the biological basis of all psychological and mental processes, to work effectively as psychotherapists - a perspective which, by the way, dates back to Freud (1895, cited after Roth 2003, p. 28). Freud had to abandon this perspective though, because neurological knowledge at his time was not sufficiently advanced (Roth 2004). As is well known, Wilhelm Reich, to whom most body-psychotherapists and psychosomatic therapists are indebted, dedicated his life's work to this view.

What brings about a destabilization of dysfunctional regulatory systems that is, a harmonization of desynchronized subsystems not accessible by consciousness? Answering this question remains a most important and difficult task for research.

Pharmacological or surgical methods, relaxation or activation techniques, Yoga practice, conditioning techniques, verbal or active interventions - we need to find out what among these practices is effective, and when and where each should be applied. How do interventions work?

\section{Cognition, Affect and Movement in the Psychotherapeutic Process}

Having ventured into neurobiological aspects of psychotherapeutic processes, I now return to the issue raised in the heading of my paper, doing so by phrasing three pointed questions:

\section{1) Cognition - Does Insight Bring about Change?}

Psychotherapists will probably agree that each presented problem calls for cognitive-verbal analysis and appraisal, including the problem's context, and 
that therapy needs to be guided by conscious strategies in order to be successful (Grawe 1998; Silberschatz et al. 1986; Crits-Christoph et al. 1988, Orlinsky et al. 1994). Whether patients also need to gain conscious insight into these relationships in order to positively change is still a matter of debate (e.g. Wallerstein 1986, 1989).

Therapists construe models of their patients' situation on the basis of verbal information. They explore their problems, intentions, motivations, goals as well as available resources by listening to the patient's narratives.

Maybe the patient changes through this process: her view of the problem, her focus of attention, her self-image (the therapist calls her attention to aspects the patient has never perceived before) and her self value (the patient maybe unfamiliar with receiving benevolent attention).

Sheer suggestions that things should be changed into a certain direction usually fail. According to Roth (2003, p. 40) they necessarily fail »because they only activate networks of the cortico-hippocampal system which is accessible to consciousness but has none or only indirect influence on limbic networks which control behavior. (...) Change in the cortico-hippocampal system only changes our declarative, explicit memory, not our behavior «. Our conscious Ego can not trace the origin of intentional sensations back to the subcortical limbic centers.

Apart from purely cognitive tasks (e.g. solving arithmetic equations or formulating texts) conscious thinking and planning (localized mainly in the dorsolateral, prefrontal cortex (mind) and the orbitofrontal cortex (reason)) play an important role in long-term definitions of goals and strategies. Longterm goals can probably only be attained if the way or the behavior to reach them are compatible with experiential entries in our - mostly unconscious emotional memory. Human behavior largely consists of automated reactions and behavior. Possibilities to change these via cognition - that is through consciousness - are limited, since most of their motives are unconscious. To instigate processes of development and change, we need corrective experiences, which are able to modify contents of the emotional and motor memory.

What we can change in psychotherapy is the interaction between our perceptive expectations as forged by previous experience and stored in memory, on one hand, and the processing of present experience, on the other hand. We do this by slowing down an ongoing experience and by focusing on the perception of single basic peripheral (close to the receptors) sensations. If a patient says: »I feel extremely bad «, the therapist can ask: »In which way exactly do you feel bad? « The patient's remark may then be specified to »I'm hardly breathing«, »I’m hunching my shoulders«, »I'm not even looking at 
you «. These latter observations refer to body facts that can be changed: If I release my shoulders, look at the other person, allow myself to breathe more deeply, how do I feel?

Consciousness - and cognitive components in psychotherapy are a part of this - is, according to Roth $(2004$, p.8), indispensable for planning actions in novel situations for which we have no routines available. By ways of our consciousness we can make predictions and anticipate long-term consequences of our decisions. Consciously perceiving the continuously manifesting stream of thoughts, feelings, postures and behavior can help to slow down automated patterns so as eventually to stop and modify them. Insight in this sense may foster change (cf. Keleman 1987).

\section{2) Emotions - Is there Healing Power in Rage?}

Emerging emotions are rooted in specific subcortical structures of the limbic system. They prepare the organism to interact with the environment in specific ways. From an evolutionary perspective they provide superiority over fixed, reflex-like stimulus-response mechanisms. They supply an intervening mode of processing, allowing the selection of more finely attuned reactions from a larger spectrum of possibilities. Motivations are predominantly triggered by internal, emotions by external stimuli. Both stimulate the organism's specific tendencies to act. Emotions can unfold remote from consciousness; they do not need linguistic codes. Neural circuits involved in emotions enable us to process environmental stimuli extraordinarily fast and can lead to extremely fast (within milliseconds) behavioral responses (e.g. Le Doux 1993, 1994, 1996).

»One of the most important aspects (...) in the functioning of the limbic system is its strong influence on various systems in the brain that control behavior. On cortical levels this exerts considerable influence on the prefrontal cortex in the emergence of desires and the maturation of intentions, as well as influencing the preand supplementary motor cortex in the immediate preparation of voluntary motor behavior. On subcortical levels, the limbic system - in a more confined sense (i.e. hypothalamus, amygdala, mesolimbic system) - controls the hippocampus and by this practically all processes of our declarative memory accessible to consciousness. Likewise, the limbic system controls the basal ganglia (...), which for their part control the prefrontal, the pre- and supplementary motor cortex in intending and predisposing for voluntary movements. In this way the limbic system has the first (...) and the final say in behavior control. Everything we do is influenced by our past emotional experience« (Roth 2004, S. 66, translated by M.K.). 
According to Roth (2003, p. 40), limbic imprints already occur during the fetal stage and predominantly during the first two to three years in life (»sensitive periods«). But also later, especially during puberty, structures of limbic networks are shaped by intense emotional distress and strong affective arousal, e.g. in life crises or traumatic experiences (also cf. Huether 1997). If psychotherapy is to influence and change such functional structures, the emotional arousal in the patient needs to attain a certain level. In my opinion, "stimulus confrontation " in behavior therapy with phobic patients is such a technique of intervention. Apart from this, I would maintain that it has mainly been humanistic schools of psychotherapy - and within these, especially body psychotherapy schools, Bioenergetic Analysis being one of the oldest ones which have developed a wide spectrum of techniques for this purpose.

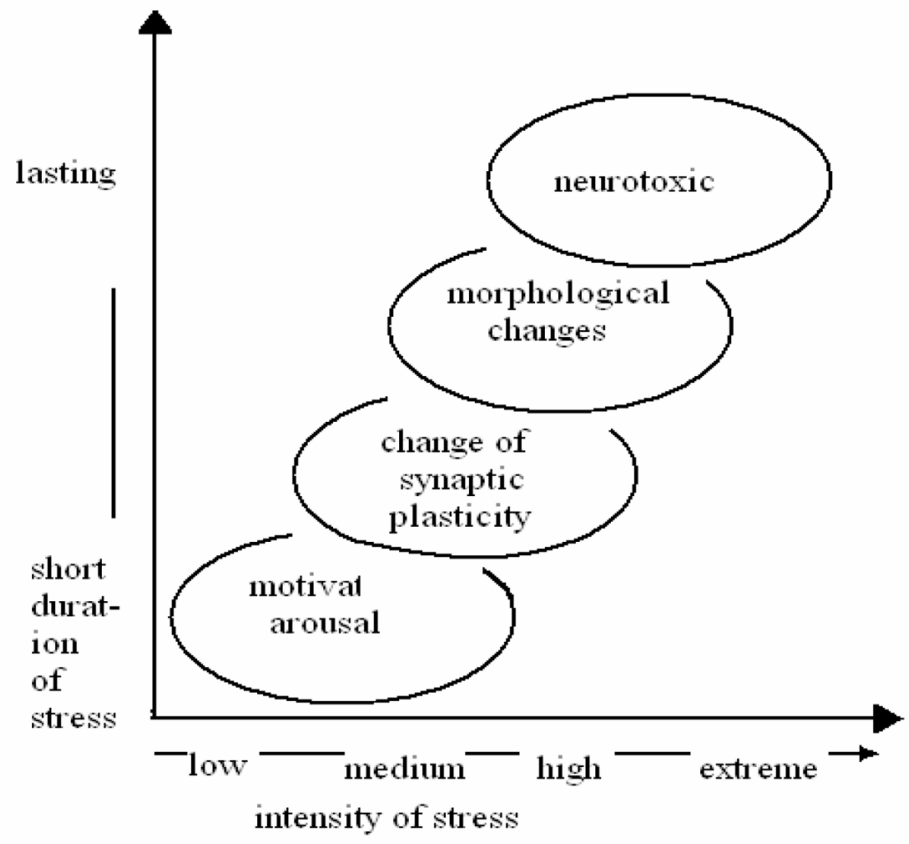

The relationship between duration and intensity of stress stimuli and their potential effect on the organism, after Kim \& Yoon 1998.

Studies dealing with neurobiological aspects of psychotherapy consistently call for »an optimal level of stress« (Fujiwara \& Markowitsch 2003, p.194), 
an »increased level of arousal «, (Schiepek et al. 2003, p.10), a »neuroendocrine reaction of stress « (Hüther 1997; Hüther \& Rüther 2003) as an indispensable prerequisite for the reorganization of neural networks. "Emotional uproar « causes an enhanced release of certain neuromodulators and neuropeptides, which effect changes in subcortical limbic centers. Our emotional experiential memory receives (according to LeDoux 1993, 1994) new entries, which - bypassing the old, dysfunctional imprints - gain increasing power in controlling our behavior.

But how can we directly influence the limbic system, which does not understand language, the emotional components of it at best, like mimics, prosody, gestures and verbally induced emotional states, ideas and images? There are a number of classical Bioenergetic exercises, which, according to clinical experience, induce arousal in the autonomous nervous system. In a pilot study (Müller \& Koemeda-Lutz 2004) at the State Hospital Münsterlingen we could demonstrate that certain Bioenergetic exercises, for instance, »bow backwards«, as well as induced hyperventilation, elicited a state of hypokapnia ${ }^{3}$, as indicated by haemal $\mathrm{CO}_{2}$-concentrations measured transcutaneously.

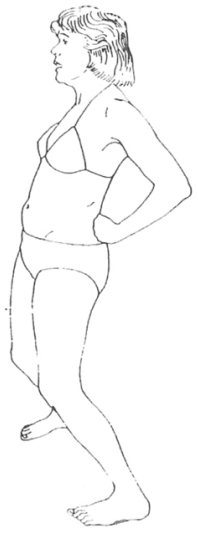

The »Bow« from Lowen A E Lowen L (1979).

3 Hypocapnia: An increase in breathing volume (voluntary ventilation, deepened breathing) causes an enlargement of the area of contact between the air and the pulmonary surface (number of capillaries) and through this increases the rate of exhalation of carbon-dioxide $\left(\mathrm{CO}_{2}\right)$. An increase in breath rate increases the rate of gas exchange. The faster air saturated with $\mathrm{CO}_{2}$ is exhaled, the faster the external air can absorb additional $\mathrm{CO}_{2}$. By this the $\mathrm{CO}_{2}{ }^{-}$ concentration in the blood decreases. 
During the »Bow backwards « the mean $\mathrm{CO}_{2}$-concentration dropped from 5.7 to $5.1 \mathrm{kPa}$ (Kilo-Pascal), with hyperventilation to $3.7 \mathrm{kPa}$. With muscle activity or expressive vocalizations the $\mathrm{CO}_{2}$-concentration rose back to normal. During the »elephant « exercise the breathing deepened and vibrations in the leg muscles became visible, but a hypocapnia state did not emerge.

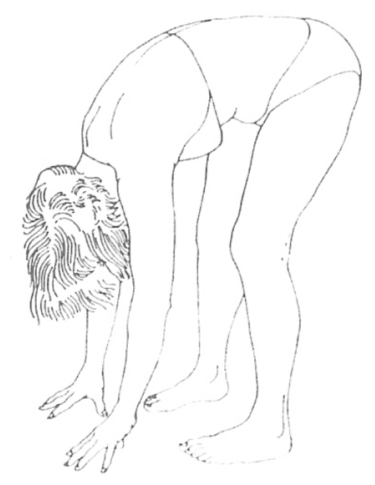

The »Elephant from Lowen A E Lowen L (1979)

From a neurological point of view hypocapnia causes states of ANSexcitability and reduces modulating and inhibiting influences from the cortex. Limbically dominated modes of processing prevail, which can, for instance, lead to emotional flooding.

Clinical Bioenergetic-Analytic experience has repeatedly demonstrated that the above-mentioned exercises lead to a loosening of affective defenses and make way for chronically suppressed emotions to be expressed. By interacting with the therapist, corrective experiences can be made - for instance: »The therapist does not get angry when I express my rage, she does not abandon me or the like."Such experiences create new entries in the emotional experiential memory.

With patients who - due to neurotic reasons - have developed an excess of inhibitions - which is true for certain patients with chronic pain (Traue 1998) - the above-mentioned techniques can be applied with the aim of freeing the expression of basic affect: e.g. the expression of anger or rage in order to enhance self assertion or to more effectively claim one's right to exist; or disgust in order to define one's boundaries and to differentiate more clearly between one's self and the other. 
For weakly structured patients, and at least at the beginning of treatment, such techniques are less indicated. These patients first need to establish some reliable bond to a trustworthy person, must build »psychic containers « big enough to tolerate and cope with intense emotions; they must develop cognitive skills which can counteract assaults from subcortically dominated information processing by contributing regulatory mechanisms and techniques.

Affective aspects in psychotherapeutic processes most often unfold on nonverbal levels. Those characterized by low levels of arousal are discussed in the relevant literature under the term of »empathy «(Lewis 2003), »right-toright-brain-communication « (Schore 2000) or »basic understanding « (Heisterkamp 2003). Those characterized by high levels of arousal would have to be subsumed under the term "catharsis", a term that was only vaguely defined and sometimes suffered undue generalization, but which has recently been elaborated on and differentiated by Klopstech (2004).

If as, therapists, we succeed in relating an aroused state to the generation of meaning (Greenberg 2002; cited in Klopstech 2004, p.7) or in helping previously suppressed affect to break through (see Traue 1998) or in giving way to new possibilities of behavior under conditions of high arousal, then - and we maintain this on the basis of what has been previously said - this directly influences the above-mentioned subcortical circuits.

After highly emotional passages in psychotherapy, integrating phases are necessary. They allow the patient to make links to existing entries in memory or to modify them. According to Klopstech (2004) already Aristotle - and contrary to his teacher Plato - attributed an insight and »new reason « promoting effect to compassion and catharsis, able to sharpen a person's critical thinking.

\section{3) Motor Activity - Can Kicking Cure?}

»We can only impact our environment by muscular movement «, says Grawe (1998, p. 181, translated by M.K.). And: »Patients change when they act differently «(Grawe. p. 93). Are there more similarities between behavioral therapy and body-psychotherapy than we have assumed so far? Anyhow, such statements seem to imply that action-oriented elements should play an important role when trying to understand and change a person's functional organization.

Recently, such considerations have gained access to psychoanalytic literature and are being discussed under the term »enactment «. The above-mentioned 
book by Heisterkamp (2002) covers this issue and can be positively recommended. Its title is "Basic Understanding « and it recommends an attentive readiness to perceive our patients' spontaneous body movements and, as therapists, to engage - partly spontaneously, partly considerately - in development-promoting dialogues of action (see also Lewis 2003). In non-verbal interactions body-oriented and interactional entries can be more easily activated in our memory than by talking. By reproducing significant early scenes or putting them »on stage in new ways, dysfunctional patterns of acting and movement can be differentiated and modified.

Let me give you a short example: A patient of about 50 years begins her 38 th session with complaints about sudden pain all over her body. The therapist suggests focusing on this pain and trying to find out to which other sensations, notions, thoughts and impulses to act it might be connected to. The patient agrees, closes her eyes and begins to deepen her breathing. After a while she says she feels that she needs to thrash around. While she tries to do this, she notices that her left arm has become completely paralyzed and that on this side she can only move her small finger a tiny bit. She says: »But I have to thrash around with my right side even more fiercely«. Which she does. After a while she calms down and utters: »I think, like with a true paralysis, I have to pick up my left with my right arm and move it«. I cannot go into further details here (see Koemeda-Lutz 2003) but want to say only this: A very early scene of interaction between mother and child emerges, accompanied by a variety of partly contradictory affective and motor impulses: abandonment, helplessness, sadness, rage, impulses to hit. And through all this a new interactive possibility emerges: Her right and her left arm can turn to each other and enter into a more constructive and, for both sides, more rewarding interaction.

The art of body psychotherapy supposedly reveals itself by the capacity to precisely perceive spontaneous expressive movements, like gestures, mimics, patterns of action and movement, which most of the time occur unconsciously and in an automated way, to compare them with the wider spectrum of human possibilities and, on the basis of these perceptions, propose an expansion of our patients' limited or dysfunctional repertoire: »Cathartic « work on high levels of arousal, considered at least in the beginnings a spectacular brand mark of Bioenergetic work, as seen in this context, is only a particular specimen of such behavioral dialogues. It perfectly meets the requirement which neurobiologists repeatedly call for: motor activity, increased arousal and »overall neural activity (Schiepek et al. 2003, p.10) as prerequisites for the reorganization of neural networks. If psychotherapy 
also generally aims at widening the scope of behavioral choices, it should include priming and practicing techniques: A person whose reaching and seizing movements in infancy went into empty space, because frequently there was no one available, actually has to learn once again to spread her arms and ask for help with open palms (and without clenching her fists). And she needs to take new risks of being frustrated, rejected or disappointed. Then she can practice and learn to master the movement itself.

\section{Closing Remarks}

A fictitious case helped to approach the question of cognitive, affective and motor components in psychotherapeutic processes. It followed an excursion into some neurobiological aspects of psychotherapeutic work. It was pointed out that personal experiences and life events can be traced to structural and functional changes in the body, especially the brain. In addition we talked about the relationship of conscious and unconscious processes in behavior control (according to G. Roth). The outstanding importance of the limbic system for personality dynamics and structure was outlined. Finally, the three components, artificially separated through my titles, were spotlighted once more by three pointed questions. Empirical studies consistently demonstrate that insight and wise intentions alone do not effect change, but that significant new emotional experiences are needed, i.e. that the limbic system must be "addressed « and that neuroplastic change can only occur under the condition of a certain degree of general arousal and can be facilitated by concomitant motor activity.

In conclusion, I recommend that equal consideration be given to cognitive, affective and motor aspects in psychotherapeutic processes and interactions and be conceptualized and implemented on these three levels.

Recent years have brought about great progress in the field of neurobiological research. Attempts to bridge the interdisciplinary gap between neuroscience and the science of psychotherapy have been made (e.g. Schiepek 2003, Koemeda-Lutz 2004). In order to let Freud's original dream (Freud 1895) of building a theory of the "psychic apparatus « on the basis of neurology come true, we still have to work hard. Nevertheless, we seem to have come a bit closer to reaching this goal in the last decades. 


\section{References}

Bandler R \& Grinder J (1981) Metasprache und Psychotherapie. Die Struktur der Magie I. Junfermann, Paderborn.

Boothe B (1991) Analyse sprachlicher Inszenierungen - Ein Problem der Psychotherapieprozessforschung. Psychotherapie - Psychosomatik - Medizinische Psychologie, 41, 22-30.

Boothe B (1993) Grundlagen einer Analyse narrativer Inszenierungen. texte. psychoanalyse, ästhetik, kulturkritik, 13 (3), 7-37.

Boothe B, Grimmer B, Luder M, Luif V, Neukom M \& Spiegel U (2002) Manual der Erzählanalyse Jakob. Version 10/02. Berichte aus der Abteilung Klinische Psychologie, Nr. 51. Zürich: Psychologisches Institut der Universität Zürich.

Ciompi L (1982) Affektlogik, Klett Cotta, Stuttgart.

Ciompi L (1997) Die emotionalen Grundlagen des Denkens - Entwurf einer fraktalen Affektlogik. Göttingen, Vandenhoeck \& Ruprecht.

Crits-Christoph P, Cooper A \& Luborsky L (1988) The accuracy of therapists' interpretations and the outcome of dynamic psychotherapy. Journal of Consulting and Clinical Psychology, 56, 490-495.

Damasio A R (1995) Descartes’ Irrtum: Fühlen, Denken und das menschliche Gehirn. List, München.

Damasio A R (2000) Ich fühle, also bin ich. Die Entschlüsselung des Bewusstseins. List. München.

Dietrich R \& Pechtl W (1990) Energie durch Übungen. Eigenverlag. Dr. R. Dietrich, Salzburg.

Dornes M (1993) Der kompetente Säugling. Fischer, Frankfurt a. M.

Dornes M (1997) Die frühe Kindheit, Fischer, Frankfurt a. M.

Freeman W J (1991) Physiologie und Simulation der Geruchswahrnehmung. In: Gehirn und Bewusstsein, Spektrum der Wissenschaft 1994, 22-31.

Freud S (1895; Erstveröff. 1950) Entwurf einer Psychologie. GW Nachtragsband. Frankfurt a.M. S.Fischer 1999, 307-477.

Fuchs E \& Flügge G (2004) Neuroforum 2: 195-199.

Fujiwara E \& Markowitsch H J (2003) Das mnestische Blockadesyndrom - hirnphysiologische Korrelate von Angst und Stress. In: Schiepek G (Herg, 2003) Neurobiologie der Psychotherapie. Schattauer, Stuttgart.

Gershon M D (1998) The second brain. Harper Collins, New York.

Gershon M D (1999) The enteric nervous system: a second brain. Hospital Practice 34 (7): $31-42$.

Grawe K (1998) Psychologische Therapie. Hogrefe, Göttingen.

Greenberg L S (2002) Integrating an Emotion-Focused Approach into Treatment. In: Journal of Psychotherapy Integration 12 (2) 154-189.

Haken H (2002) Synergetik der Gehirnfunktionen. In: Schiepek G (Herg, 2003) Neurobiologie der Psychotherapie. Schattauer, Stuttgart.

Heisterkamp G (2002) Basales Verstehen. Handlungsdialoge in Psychotherapie und Psychoanalyse. Pfeiffer bei Klett-Cotta, Stuttgart.

Horowitz M J (1987) States of Mind. Analysis of Change in Psychotherapy. Plenum Medical Book Company, New York.

Hüther G (1997) Biologie der Angst: Wie aus Stress Gefühle werden. Vandenhoek \& Ruprecht, Göttingen. 
Hüther G \& Rüther E (2003) Die nutzungsabhängige Reorganisation neuronaler Verschaltungsmuster im Verlauf psychotherapeutischer und psychopharmakologischer Behandlungen. In: Schiepek G (Herg, 2003) Neurobiologie der Psychotherapie. Schattauer, Stuttgart.

Johnson S M (1994) Character Styles. Norton, New York.

Keleman (1986) Bonding: A Somatic emotional approach to transference. Center Press, Berkeley.

Keleman S (1987) Embodying Experience. Forming a Personal Life. Center Press, Berkeley.

Kim J J \& Yoon K S (1998) Stress: metaplastic effects in the hippocampus. In: Trends Neurosci 21: 505-509.

Klopstech A (2002) Modelle therapeutischen Handelns: Der psychoanalytische und der bioenergetische Weg. In: Koemeda-Lutz (Hrsg) Körperpsychotherapie - Bioenergetische Konzepte im Wandel. Schwabe Basel.

Klopstech A (2004) Im Kontext autonomer und interaktiver Selbstregulation: Katharsis im neuen Kleid. In:Geissler, P. (Hg.) (2004): Was ist Selbstregulation? Giessen, Psychosozial Verlag, S.95-119.

Koemeda-Lutz M (Hrsg 2002) Körperpsychotherapie - bioenergetische Konzepte im Wandel. Schwabe Verlag, Basel.

Koemeda-Lutz M (2003) Die Bedeutung des Körpers in der Psychotherapie. Baustein zum Weiterbildungszyklus »Psychosomatik « an der Klinik für Psychiatrie und Psychotherapie Littenheid TG.

Koemeda-Lutz M (Hrsg 2004) Psychotherapie Forum 12 (2) Themenheft: Neurowissenschaften und Psychotherapie.

Koemeda-Lutz M (2005) Die relative Bedeutung von Kognition, Affekt und Motorik im psychotherapeutischen Prozess - eine bioenergetische Perspektive. 183-202 in Geißler P $(\mathrm{Hg})$ Nonverbale Interaktion in der Psychotherapie - Forschung und Relevanz im therapeutischen Prozess. Psychosozial-Verlag, Gießen.

Lambertz M, Langhorst P (1998) Simultaneous changes of rhythmic organiszation in brainstem neurons, respiration, cardiovascular system and EEG between $0.05 \mathrm{~Hz}$ and $0.5 \mathrm{~Hz}$. In: J Autonom Nervous Sys (68) 58-77.

Lambertz M, Vandenhouten R, Grebe R, Langhorst P (2000) Phase transitions in the common brainstem and related systems investigated by nonstationary time series analysis. In: J Autonom Nervous Sys (78) 141-157.

Langhorst P, Lambertz M, Schulz G (1987) Role played by amygdale complex and common brainstem system in integration of somatomotor and autonomic components of behavior. In: Ciriello J, Calaresu F R, Renaud L P Polosa C (Eds). Organization of the Autonomic Nervous System: Central and Peripheral Mechanisms: Alan R. Liss Inc., New York, 347-361.

Ledoux J (1993) Emotional Memory Systems in the Brain. In: Behavioral Brain Research 58.

Ledoux J (1994) Emotion, Memory and the Brain. In: Scientific American, Juni.

Ledoux J E (1996) The emotional brain: The mysterious underpinnings of emotional life. New York, NY, Simon \& Schuster.

Lewis R (2003) The Anatomy of Empathy. Lecture given on October 11th at the 17th IIBA Conference in Salvador Bahia; wird publiziert in Bioenergetic Analysis. The Clinical Journal of the IIBA 2005.

Lowen A \& Lowen L (1979) Bioenergetik für jeden, Kirchheim, München.

Lowen A (1981) Körperausdruck und Persönlichkeit: Grundlagen und Praxis der Bioenergetik. Kösel, München. Engl.: The Language of the Body. Grune and Stratton, New York, 1958. 
Mayer E A (1999) Emerging disease model for functional gastrointestinal disorders. American Journal of Medicine 107 (5A): 12-19.

Martin-Sölch C (2004) Neurowissenschaftliche Aspekte der Emotionsregulation. In Psychotherapie Forum 12 (2) 71-78.

Müller F \& Koemeda-Lutz (2004) Pilotversuch zur Hypokapnie-Induktion durch bioenergetische Übungen am Kantonsspital Münsterlingen, Abt. Neurologie, unveröffentlicht.

Orlinsky D E, Grawe K, \& Parks B (1994) Process and Outcome in Psychotherapy - noch einmal. In: Bergin A E \& Garfield S L (Eds.) Handbook of Psychotherapy and Behavior Change. Wiley, New York.

Reich W (1933) Charakteranalyse. Kiepenheuer und Witsch, Köln 1971.

Roth G (1994) Das Gehirn und seine Wirklichkeit: kognitive Neurobiologie und ihre philosophischen Konsequenzen. Suhrkamp, Frankfurt a. M.

Roth G (2001) Fühlen, Denken, Handeln: Wie das Gehirn unser Verhalten steuert. Suhrkamp, Frankfurt a. M.

Roth G (2003) Wie das Gehirn die Seele macht. In: Schiepek G (Herg, 2003) Neurobiologie der Psychotherapie. Schattauer, Stuttgart.

Roth G (2004) Das Verhältnis von bewusster und unbewusster Verhaltenssteuerung. Psychotherapie Forum. Themenheft: Neurowissenschaften und Psychotherapie. KoemedaLutz M (Hrsg) Springer Wien Vol. 12 (2) 59-70.

Ruegg J C (2001) Psychosomatik, Psychotherapie und Gehirn: neuronale Plastizität als Grundlage einer biopsychosozialen Medizin. Schattauer, Stuttgart.

Schiepek G (Herg. 2003) Neurobiologie der Psychotherapie. Schattauer, Stuttgart.

Schiepek G, Lambertz M, Perlitz V, Vogeley K \& Schubert C (2003) Neurobiologie der Psychotherapie - Ansatzpunkte für das Verständnis und die methodische Erfassung komplexer biopsychischer Veränderungsprozesse. 1-27 in: Schiepek G (Herg. 2003) Neurobiologie der Psychotherapie. Schattauer, Stuttgart.

Schore A N (1994) Affect regulation and the origin of the self: the neurobiology of emotional development. Erlbaum, Hillsdale NJ.

Schore A N (2003) Affect regulation and the repair of the self. W.W. Norton \& Co., New York.

Schulz G, Lambertz M, Stock G, Langhorst P (1986) Neuronal Activity in the Amygdala related to somatomotor and vegetative Components of Behavior in Cats. J Autonom Nervous Sys, Suppl, 639-648.

Siegel D J (1999) The developing mind: toward a neurobiology of interpersonal experience. Guilford Press, New York.

Silberschatz G, Fretter P B \& Curtis J D (1986) How do interpretations influence the process of psychotherapy? Journal of Consulting and Clinical Psychotherapy 54, 646-652.

Skinner B F (1953) Science and human behavior. Macmillan, New York.

Skinner B F (1971) Beyond freedom and dignity. Alfred A. Knopf, New York.

Skinner B F (1974) About behaviorism. Alfred A. Knopf, New York.

Spitzer M (2002) Lernen - Gehirnforschung und die Schule des Lebens. Spektrum Akademischer Verlag, Heidelberg.

Stern D (1992) Die Lebenserfahrung des Säuglings. Klett-Cotta, Stuttgart.

Traue HC (1998) Emotion und Gesundheit: die psychobiologische Regulation durch Hemmungen. Spektrum Akademischer Verlag, Heidelberg.

Vaitl D, Schienle A \& Stark R (2003) Emotionen in der Psychotherapie: Beiträge des Neuroimaging. 158-185 in: Schiepek G (Herg 2003) Neurobiologie der Psychotherapie. Schattauer, Stuttgart. 
Is there Healing Power in Rage?

Vandenhouten R (1998) Analyse instationärer Zeitreihen komplexer Systeme und Anwendungen in der Physiologie. Aachen: Shaker Verlag.

Vandenhouten R, Lambertz M, Langhorst P, Grebe R (2000) Nonstationary time-series analysis applied to investigation of brainstem system dynamics. IEEE Trans Biomed Eng (47) 729-737.

Waechter F K (1978) Ich liebe das Leben. In: Wahrscheinlich guckt wieder kein Schwein. Diogenes, Zürich.

Wallerstein R S (1986) Forty-two lives in treatment: A study of psychoanalysis and psychotherapy. Guilford, New York.

Wallerstein R S (1989) The Psychotherapy Research Program (PRP) of the Menninger Foundation: An overview. Journal of Consulting and Clinical Psychology 57, 195-205.

\section{About the Author}

Margit Koemeda-Lutz is a licensed psychotherapist in private practice, trainer for the Swiss Society for Bioenergetic Analysis and Therapy (SGBAT) and faculty member of the IIBA. She has been teaching in Switzerland, Germany and Austria. Founding member of the interdisciplinary annual psychotherapy conferences »Breitensteiner Psychotherapiewochen 1981-2000 «; member of the executive committee SGBAT 1994-2001; active in two evaluation studies on the effectiveness of outpatient psychotherapy in Switzerland and Germany, one of which won the usabp research award in 2005; editor of Bioenergetic Analysis and on the editorial board of »Psychotherapie Forum«.

Dr. Dipl.Psych. Margit Koemeda-Lutz

Breitenstein

Fruthwilerstrasse 70

CH-8272 Ermatingen

koemeda@bluewin.ch 